\title{
Localization of a Potyvirus and the Viral Genome-Linked Protein in Wild Potato Leaves at an Early Stage of Systemic Infection
}

\author{
Minna-Liisa Rajamäki and Jari P. T. Valkonen \\ Department of Plant Biology, Genetics Centre, SLU, PO Box 7080, S-750 07 Uppsala, Sweden, and Department of \\ Applied Biology, PO Box 27, FIN-00014 University of Helsinki, Finland
}

Submitted 19 June 2002. Accepted 6 September 2002.

\begin{abstract}
The upper noninoculated 'sink' leaves of the wild potato species, Solanum commersonii, were studied for distribution of Potato virus $A$ (PVA) at an early stage of systemic infection. Viral RNA was detected by in situ hybridization, and five viral proteins were localized using immunohistochemical staining in leaf sections. Initial systemic infection foci were found at the vicinity of major and minor veins. In these infection foci, the viral coat protein, cylindrical inclusion protein, and helper component-proteinase colocalized with viral RNA in parenchyma and mesophyll cells, but none of these were detected in companion cells $(\mathrm{CC})$. In contrast, VPg, which is the N-proximal half of the NIa protein (separated from the $\mathrm{C}$-terminal proteinase domain, NIapro, by an autocatalytic cleavage) and acts as a viral genome-linked protein, was detected in $\mathrm{CC}$ in the infection foci, but only at an early stage of virus unloading. Outside the infection foci, conspicuous signals for VPg were readily and exclusively detected in $\mathrm{CC}$ of many veins in all vein classes in the absence of signals for NIapro, other viral proteins, and viral RNA. Taken together, our data indicate that both major and minor veins may unload PVA in the sink leaves of potato. The data suggest that VPg is translocated from inoculated source leaves to the sink leaves, where it accumulates in $\mathrm{CC}$ at an early stage of systemic infection. These findings suggest that VPg may be a 'phloem protein' that specifically acts in $\mathrm{CC}$ in the sink leaves to facilitate virus unloading.
\end{abstract}

Viruses invade plants via the vascular system after having established infection at the site of inoculation. As the leaves mature, they undergo a sink-source transition from net importers of carbon to carbon exporters, which determines the direction of photoassimilate transport (Turgeon 1989) and also the transport of viruses in the vasculature (Ruiz-Medrano et al. 2001). Long distance transport of photoassimilates and viruses occurs in conducting sieve elements (SE), which are specialized, elongated, enucleate cells lacking ribosomes (Van Bel et al. 2002). Each SE is supported by ontogenically related companion cells (CC) through the interconnecting plasmodesmata (PD). The CC-SE complex is embedded in the vascular tissue (e.g., veins in leaves) and is connected to other vascular cells via $\mathrm{PD}$ from $\mathrm{CC}$. Thus, following the long distance transport in $\mathrm{SE}$, viruses must exit a CC-SE complex to initiate infection at new sites (Nelson and van Bel 1998; Oparka and Santa Cruz 2000; Santa Cruz 1999).

Corresponding author: Jari Valkonen; E-mail: jari.valkonen@vbiol.slu.se.
Recent studies indicate that viruses, solutes, and macromolecules may all use the same unloading pathway in sink leaves (Imlau et al. 1999; Oparka et al. 1999; Roberts et al. 1997). Fluorescent phloem-mobile solutes, Potato virus $X$ (PVX, genus Potexvirus) and Tobacco mosaic virus (TMV, genus Tobamovirus) are unloaded exclusively from major veins (class III and larger) in the sink tissues of Nicotiana benthamiana (Cheng et al. 2000; Roberts et al. 1997). The green fluorescent marker protein (GFP) expressed under a CC-specific promotor in transgenic Arabidopsis thaliana and N. tabacum enters SE and is translocated via vasculature to the sink leaves, where it is unloaded from major veins (Imlau et al. 1999; Oparka et al. 1999). However, some plant systems or plant-virus combinations show different unloading patterns of photoassimilates or viruses, or both, in the sink leaves. In Beta vulgaris, imported labeled photoassimilates are unloaded mainly via the class IV veins in young sink leaves, but within the zone of the leaf undergoing sink-source transition, the smallest veins (class V) are also used for unloading in the importing regions (Schmalstig and Geiger 1987).

Vascular transport of viruses refers to viral invasion of vascular cells prior to and after long distance transport via SE. Transport via SE is believed to occur passively (Carrington et al. 1996), but some studies have proposed an active involvement of host factors (Nelson and van Bel 1998). The vascular tissue consists of several types of cells, such as SE, CC, parenchyma cells (P), and bundle sheath cells (BS) (e.g., Figs. 1F and 2E) (McCauley and Evert 1988a, 1988b, 1989). The movement between specific types of cells, such as between the CC-SE complex and $\mathrm{P}$, may involve differential regulation (Ruiz-Medrano et al. 2001). Therefore, viruses encode movement proteins (MPs) that facilitate viral cell-to-cell movement. Many MPs increase the molecular size exclusion limit (SEL) of PD between mesophyll cells and suppress the expression of viral genomes during the transport process (Karpova et al. 1997, 1999; Lazarowitz and Beachy 1999; Rhee et al. 2000; Tzfira et al. 2000; Waigmann et al. 2000). Similar functions of the MPs are conceivable during viral cell-to-cell movement between vascular cells, but it has been little studied.

Viral MPs, such as the TMV 30K MP, are targeted proteins that may directly interact with PD components and manipulate SEL to achieve their own transport (Crawford and Zambryski 2000). In contrast, nontargeted proteins diffuse passively through dilated PD, which is greatly affected by leaf age, plant growth condition and stress, plant species, and the dimensions of the protein (Crawford and Zambryski 2001; Ruiz-Mendrano et al. 2001). PD in sink leaf tissues are more permissive than those in source tissues to the intercellular movement of nontargeted 
proteins (Crawford and Zambryski 2001). Diffusion of GFP (27 $\mathrm{kDa}$ ) from $\mathrm{SE}$ to $\mathrm{CC}$ has been reported, whereas the exit of proteins from the CC-SE complex to other vascular cells may be more restricted (Imlau et al. 1999; Oparka et al. 1999).

Potyviruses (genus Potyvirus, family Potyviridae) encode several proteins involved in virus transport. The coat protein
(CP), cylindrical inclusion protein (CI), and the helper component-proteinase (HCpro) have been implicated in cell-to-cell movement in mesophyll tissues (Carrington et al. 1998; Dolja et al. 1995; Rojas et al. 1997; Varrelmann and Maiss 2000). HCpro is also required for vascular movement (Cronin et al. 1995; Kasschau et al. 1997), perhaps due to its antiviral silencing
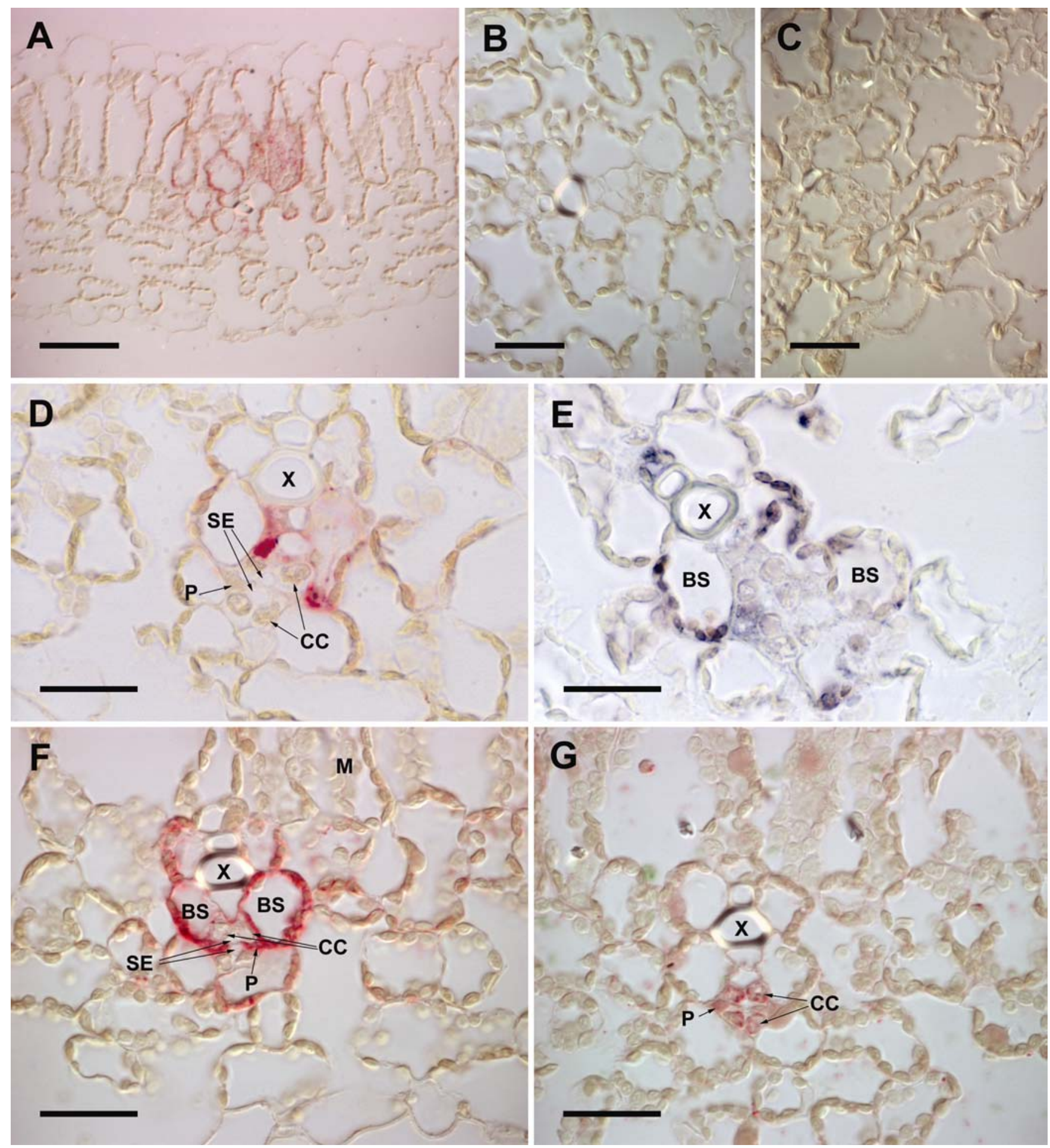

Fig. 1. Immunohistochemical localization of coat protein $(\mathrm{CP})$ and genome-linked protein $(\mathrm{VPg})$ and detection of viral RNA by in situ hybridization in the upper noninoculated leaves of Solanum commersonii at an early stage of systemic infection with Potato virus A (PVA). A, A representative view on an initial systemic infection site localized at a vein of class IV (immunostaining with anti-CP antibodies). B, and C, Noninfected leaf tissue stained with antibodies to CP and VPg, respectively, and showing no signals. The signals of $\mathbf{D}$, immunostaining for CP and $\mathbf{E}$, in situ hybridization for viral RNA colocalize in the consecutive sections (minor vein, class VI). At sites where systemic infection was apparently initiated very recently, staining for $\mathbf{F}$, CP reveals signals in parenchyma (P) and bundle sheath (BS) cells, whereas staining for G, VPg is observed in companion cells (CC) (vein class VII). M = mesophyll cell, $\mathrm{SE}=$ sieve element, and $\mathrm{X}=$ xylem vessel. Scale bars $=50 \mu \mathrm{m}$ in $\mathrm{A}$ and $25 \mu \mathrm{m}$ in B to $\mathrm{G}$. 
suppression activity in vascular cells (Kasschau and Carrington 2001). The functions of $\mathrm{CP}$ in viral movement and virion assembly cannot be separated (Varrelmann and Maiss 2000), and therefore, it is possible that the cell-to-cell and long distance transport of potyviruses may occur as virions (Carrington et al. 1996; Varrelmann and Maiss 2000). However, the transportable form of potyviruses between vascular cells and over long distance via SE is not yet resolved.
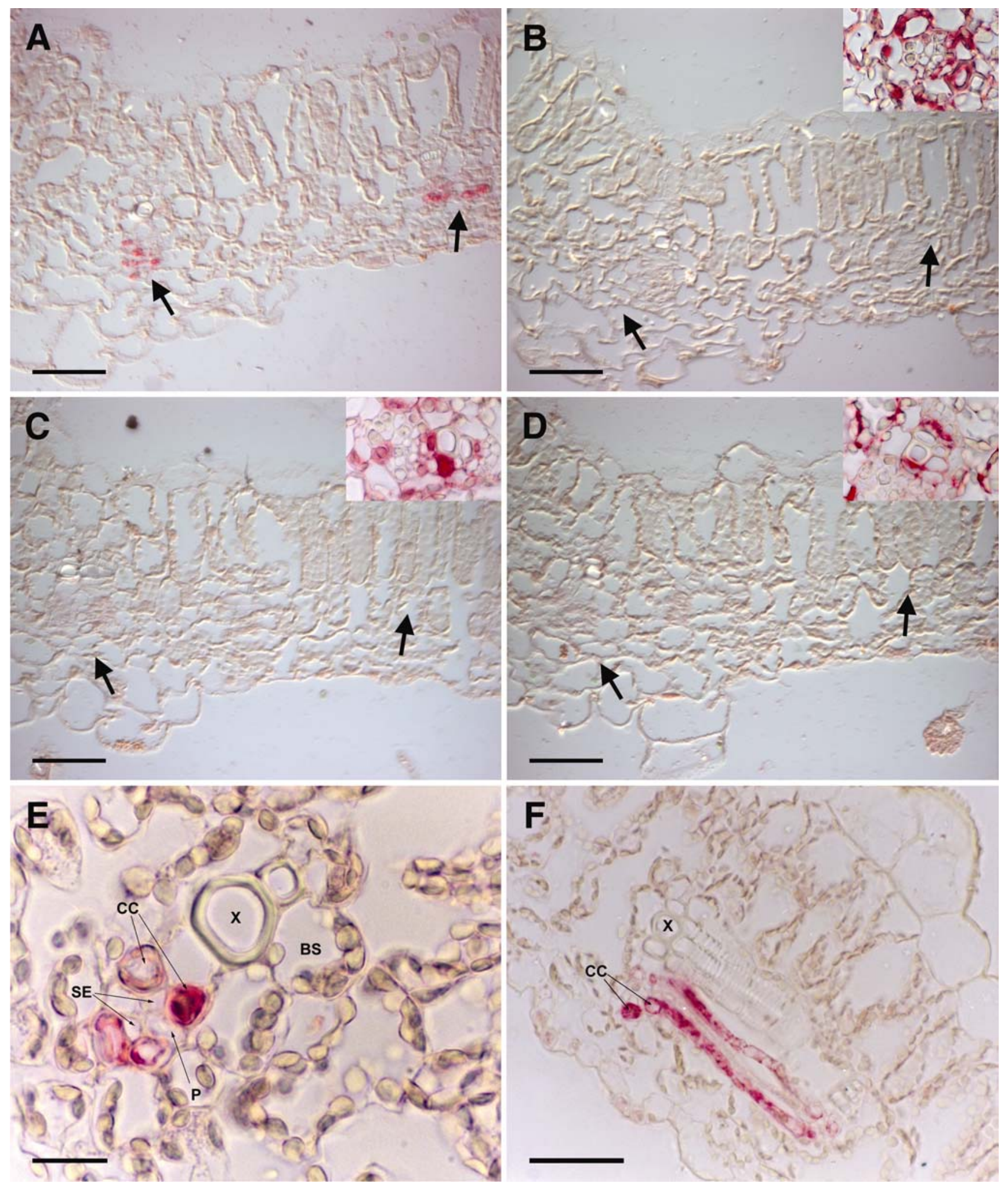

Fig. 2. Conspicuous staining of companion cells (CC) exclusively with anti-genome-linked protein (VPg) antibodies in the upper noninoculated leaves. A, Exclusive staining of CC in a major vein of class III (arrowhead to the left) and a minor vein of class VI to V (to the right). Consecutive sections were stained with antibodies to $\mathbf{B}$, coat protein (CP), $\mathbf{C}$, helper component-proteinase HCpro, and $\mathbf{D}$, cylindrical inclusion protein (CI), but no signals were observed. (The inserts in B through D show staining of mesophyll cells with antibodies to CP, HCpro, and CI, respectively, in leaves systemically infected with Potato virus A). In $\mathbf{E}$, cross-sections and $\mathbf{F}$, longitudinally cut sections of the smallest veins (class VI to VII), it was also apparent that staining with antibodies to VPg was confined to $\mathrm{CC}$. $\mathrm{BS}=$ bundle sheath cell, $\mathrm{P}=$ parenchyma cell, $\mathrm{SE}=$ sieve element, and $\mathrm{X}=\mathrm{xylem}$ vessel. Scale bars $=50 \mu \mathrm{m}$ in $\mathrm{A}$ to $\mathrm{D}, 10 \mu \mathrm{m}$ in $\mathrm{E}$, and $25 \mu \mathrm{m}$ in $\mathrm{F}$. 
The genome-linked protein ( VPg) of potyviruses is implicated in cell-to-cell movement (Nicolas et al. 1997) and vascular movement of potyviruses (Rajamäki and Valkonen 1999, 2002; Schaad and Carrington 1996; Schaad et al. 1997). It is the N-terminal half of the nuclear inclusion protein a (NIa) that is autocatalytically processed by the C-terminal proteinase domain (NIapro). VPg may act as a primer for viral RNA synthesis (Li et al. 1997; Fellers et al. 1998; Paul et al. 1998), but it is not known whether the potyviral VPg carries out this putative function as part of NIa or as a mature VPg. Also, it is not known at which stage of the viral replication cycle VPg is separated from NIapro, but apparently, only the VPg separated from NIapro is found bound to the $5^{\prime}$ end of the viral genome in virions of Tobacco vein mottling virus (Murphy et al. 1991, 1996) and Potato virus A (PVA) (Oruetxebarria et al. 2001). Hence, VPg may be a component of the putative ribonucleoprotein complex of potyviruses transported in plants.

Virus localization has been carried out on inoculated leaves to resolve the route for, or cell barriers preventing, phloemloading of potyviruses (Andersen and Johansen 1998; Cronin et al. 1995; Ding et al. 1998; Masuta et al. 1999; Murphy and Kyle 1995; Schaad and Carrington 1996; Rajamäki and Valkonen 2002). However, fewer studies have investigated unloading of potyviruses in the sink tissues. Therefore, the aim of this study was to detect initial systemic infection sites in the upper noninoculated leaves of Solanum commersonii plants inoculated with PVA. PVA infects species of the family Solanaceae and occurs in potatoes (Solanum tuberosum) in many areas of the world (Bartels 1971). We used immunolocalization of VPg, NIapro, CP, HCpro, and CI and in situ hybridization for detection of viral RNA, to localize initial infection sites in leaves that first become systemically infected with PVA. Our data indicate that initial infection foci are associated with all vein classes in S. commersonii. Detection of VPg in CC in the absence of detectable accumulation of other viral proteins and viral RNA suggested that long distance transport of VPg may occur from the source leaves and that accumulation of VPg in $\mathrm{CC}$ in the sink leaves may be important for virus unloading.

\section{RESULTS}

\section{Detection of infection foci in upper noninoculated leaves at an early stage of systemic infection.}

The samples for this study were collected from those expanding leaves that first became systemically infected. Systemic infection was not detected in any leaf by enzyme-linked immunosorbent assay (ELISA) using anti-CP antibodies at 14 days postinoculation (dpi), but it was detected in one to three upper leaves at $17 \mathrm{dpi}$. Additional leaflets from these viruspositive leaves were sampled the following day (the day after the first sampling). Tissue was excised from the basal part of the leaflets, avoiding the tips of leaflets since some of them might have been in transition from a sink to a source (Roberts et al. 1997). The leaf pieces were fixed immediately. The remainder of the leaflets from which tissue had been excised was tested using reverse transcription polymerase chain reaction to confirm that they contained PVA. Immunolocalization studies were carried out using polyclonal antibodies to $\mathrm{CP}, \mathrm{VPg}$, NIapro, CI, and HCpro. In addition, several sections were stained using in situ hybridization with an RNA probe complementary to the PVA CP-encoding sequence. The details of methods used in this study have been described elsewhere (Rajamäki and Valkonen 2002).

Typically, in the view across each section, 1 vein of class 2 , 0 to 3 veins of class 3 , and 15 to 25 smaller veins were observed. In each leaf piece, approximately 40 different veins were analyzed (5 to $50 \%$ of each leaf piece was sectioned, in- cluding different parts). In the whole study, a total of 68 tissues were analyzed, yielding observations on approximately 2,700 veins.

Consistent with sampling having taken place at an early stage of systemic infection, many leaf pieces $(5 \mathrm{~mm} \times 5$ to 10 $\mathrm{mm}$ ) contained no detectable infection foci (two to three leaf pieces taken from each leaflet). In the first experiment, infection foci were detected with anti-CP antibodies in 5 out of 53 leaf pieces (eight plants) analyzed. In the second experiment, a higher portion of leaves contained detectable infection foci (4 of the 15 leaf pieces studied from five plants). In those nine tissues that showed staining for $\mathrm{CP}$ in at least some veins, a total of approximately 300 veins were examined with signals for $\mathrm{CP}$ detected in 128 veins (Table 1). In some sections, the tissue between the veins showed CP-specific signals, indicating that infection had spread, and identification of the initial site of systemic infection was not possible. However, in many cases, only a limited number of vein cells and mesophyll cells immediately adjacent to the vein were stained, while the surrounding tissues did not show staining (Fig. 1A, 1D, and 1F). These sites were considered to be systemic infection foci representing an early stage of infection.

Serial sections were stained with antibodies to CP, HCpro, and CI that were readily colocalized in the infection foci, the signals being fairly similar in their strength (data not shown). Also, in views on sections where larger areas of tissues were stained, intensity and distribution of signals for $\mathrm{CP}, \mathrm{HCpro}$, and CI (inserts in Fig. 2B, 2C, and 2D, respectively) were rather similar. Signals obtained by in situ hybridization for viral RNA colocalized with the signals obtained with immunostaining for $\mathrm{CP}$ in the infection foci (Fig. 1D compared with 1E), CI, and HCpro. Staining with the antibodies to VPg did not always show signals in the cells that were stained with antibodies to $\mathrm{CP}$ (Fig. 1F compared with $1 \mathrm{G}$ ) or other PVA proteins and RNA in the consecutive sections of infection foci. On the other hand, staining for VPg was observed in CC (Fig. 1G) that showed no signal for $\mathrm{CP}(\mathrm{Fig}$. $1 \mathrm{~F})$ or other PVA proteins and RNA. No staining was observed in sections prepared from healthy leaves, indicating that the antibodies and the probe were specific to the PVA proteins and the RNA, respectively.

In mesophyll cells, the signals for VPg (Fig. 3H) and NIapro (Fig. 3J) were largely confined to small, distinct, single spots that possibly represented nuclei. The potyviral VPg contains a nuclear localization signal (NLS) that, in the PVA VPg, is likely formed by amino acids 41 to 50 (KKGKTKGKTH), with a sequence that is quite similar to the NLS (NKGKRKGTTR; amino acids 40 to 49) identified in VPg of Tobacco etch potyvirus (TEV) (Schaad et al. 1996). The processed NIapro lacks an NLS, and supposing that the intensely stained compartment of the cell represents the nucleus, the similar cellular localization of signals for NIapro (Fig. 3J) and VPg suggests that the unprocessed NIa is translocated to nuclei in PVA-infected mesophyll cells, similar to TEV (Carrington et al. 1993; Schaad et al. 1996).

\section{Association of infection foci with different vein classes.}

The vein classification in the leaves of cultivated potato $(S$. tuberosum) (Hayward 1938; McCauley and Evert 1988a, 1988b, 1989) and S. commersonii (Rajamäki and Valkonen 2002) have been described. Major veins are those containing rib tissue, whereas minor veins are entirely embedded in mesophyll tissue. In $S$. commersonii, seven vein classes can be recognized (mid-rib = class I) (Rajamäki and Valkonen 2002).

Careful analysis of approximately 2,700 major or minor veins (classes II to VII) was made to detect the vein classes associated with infection foci (discussed above) and, thus, conceivably able to unload PVA. Infection foci were associated 
with all vein classes studied (Table 1). Some of the class IV to $\mathrm{V}$ veins contained a limited amount of rib tissue in contrast to others, suggesting that these vein classes could belong to major or minor veins, respectively, as described previously (McCauley and Evert 1988a). Infection foci were analyzed using consecutive sections to ensure that the vein was one in which virus unloading initiating infection had occurred. These data suggest that, at least at some developmental stage, minor veins (classes IV to VII) of $S$. commersonii can unload PVA, unlike Nicotiana spp., which unload viruses (PVX and TMV) predominantly from the major veins of class III (Cheng et al. 2000; Roberts et al. 1997).

\section{Conspicuous accumulation of VPg in companion cells.}

In the highest order minor veins (classes VI to VII) of potato, the anatomy of abaxial phloem (ABph) is highly consistent regarding cell arrangement (McCauley and Evert 1989), which makes it possible to identify cells according to their position. In addition, CC commonly appear denser than the neighboring phloem parenchyma cells due to a high number of mitochondria, plastids, and ribosomes in the cytoplasm and have a rather uniform shape of oval or nearly round (Fig. 1D, 1F and 2E) (McCauley and Evert 1989).

In contrast to infection foci that were detected in only a few leaf pieces analyzed, many veins in most leaf pieces showed conspicuous signals for VPg only. As explained, the infection foci were detected based on the positive signals for $\mathrm{CP}, \mathrm{CI}$, HCpro, and viral RNA in vascular cells (except $\mathrm{CC}$, in which no signals were observed) and in a few mesophyll cells surrounding the unloading vein (Fig. 1A, 1D, and 1E). In contrast, $\mathrm{CC}$ in minor veins were strongly stained when anti-VPg antibodies were used (Fig. 2A, 2E, and 2F), but no staining of CC (including in the $\mathrm{CC}$ showing the conspicuous signals for $\mathrm{VPg}$ ), other vascular cells, or the surrounding mesophyll cells was observed with antibodies to other PVA proteins (Fig. 2B, $2 \mathrm{C}$, and $2 \mathrm{D}$ ) or when using in situ hybridization. In the major veins, the signals for VPg were observed in the vascular bundles of ABph (Fig. 3A, 3D, and 3F), but staining with antibodies to NIapro (Fig. 3E and 3G), CP (Fig. 3B), CI, HCpro, or in situ hybridization (Fig. 3C) revealed no signals. The veins showing staining for VPg in CC represented over $70 \%$ of all veins in which virus-specific signals were detected and were similarly distributed in all vein classes (Table 1).

\section{Detection sensitivity: CP and VPg.}

We reasoned that the observed presence of VPg and the absence of other PVA proteins in the CC of many veins might be an artifact due to differences in detection sensitivity. This possibility was investigated first by titration of the anti-CP and anti-VPg antibodies against equal amounts of purified recombinant CP and VPg $(6 \times$ His-CP and MBP-VPg) (Merits et al. 1998, 1999). Data indicated that the anti-VPg antibodies could detect approximately 50-fold lower amounts of the corresponding antigen than did the anti-CP antibodies. While these results suggest that low amounts of $\mathrm{CP}$ might remain undetected in the presence of low but detectable amounts of VPg in the immunostaining experiments, other results suggest otherwise. During PVA replication, all the antigens corresponding to the antisera used in this study are produced in equimolar amounts (Shukla et al. 1994). However, in the infection foci, CP (and CI and HCpro) was readily detected in many cells, whereas weak or no signals for VPg were observed in the same cells (Fig. 1F compared with 1G). Thus, in the fixed, embedded leaf tissues, detection of VPg by immunostaining was apparently less sensitive than detection for $\mathrm{CP}$ and the other PVA proteins. In immunostaining, detection sensitivity may be different from in vitro assays, because the accessibility of antibodies to the antigen may be affected by subcellular localization of the antigen (VPg is targeted to nucleus) or its presence in complexes with other proteins. CP and VPg are posttranslationally modified in plant cells (Ivanov et al. 2001), and fixation procedures may modify epitopes affecting antibody binding. Furthermore, CP assembles to particles and HCpro and CI form inclusions in the cytoplasm of infected cells (Shukla et al. 1994). The multimers of these proteins may allow multiple antibody-antigen interactions strengthening the signal. All data considered, the specific staining of CC exclusively with the anti-VPg antibodies was most likely not an artifact resulting from disparities in the sensitivity of the antibodies to VPg and other PVA proteins.

\section{DISCUSSION}

Our data show that infection foci at an initial stage of systemic infection with PVA in the leaves of a wild potato species, Solanum commersonii, are associated with major and minor veins, suggesting that both may unload PVA. These data differ from the previous studies on viral, solute, and macromolecule unloading in Nicotiana species, which showed unloading occurring exclusively from the major veins (Imlau et al. 1999; Oparka et al 1999; Roberts et al. 1997). In N. benthamiana, minor veins do not receive GFP-tagged PVX via phloem but get infected through local cell-to-cell movement of the virus (Roberts et al. 1997), which was not observed with PVA in our study. On the other hand, our results are similar to those from studies of the transport and unloading of photoassimilates in Beta vulgaris, in which imported, labeled photoassimilates are transported mainly via class IV veins in young sink leaves, but also in the leaf tissue undergoing sink-source transition in the importing leaves with the smallest veins (class V) also becoming successively engaged in unloading (Schmalstig and Geiger 1987). The phloem-limited viruses are shown to infect minor veins. Bean dwarf mosaic virus (DNA genome, genus Begomovirus) tagged with GFP is detected along veins of all classes (I to V) in systemically infected sink leaves of Phaseolus vulgaris (Sudarshana et al. 1998). Potato leaf roll virus (PLRV) (RNA genome, genus Polerovirus) infects the minor veins in N. benthamiana (Savenkov and Valkonen 2001). Thus, there may be differences in viral transport depending on the virus, host species, and the developmental stage of the importing sink leaf (Schmalstig and Geiger 1987; Sudarshana et al. 1998).

Table 1. Detection of Potato virus A genome-linked protein (VPg) and coat protein (CP) in the upper noninoculated leaves of Solanum commersonii

\begin{tabular}{lccr}
\hline Vein class & VPg detected exclusively in CC & VPg and CP detected $^{\mathbf{b}}$ & Total no. veins $^{\mathbf{c}}$ \\
\hline II & $34(79 \%)$ & $9(21 \%)$ & 43 \\
III & $38(70 \%)$ & $16(30 \%)$ & 54 \\
IV to V & $252(83 \%)$ & $53(17 \%)$ & 305 \\
VI to VII & $432(90 \%)$ & $50(10 \%)$ & 482 \\
\hline
\end{tabular}

\footnotetext{
${ }^{a}$ Immunostaining signals were detected only with anti-VPg antibodies and were exclusively detected in companion cells (CC).

${ }^{\mathrm{b}}$ Immunostaining signals were detected with anti-VPg and anti-CP antibodies in vascular parenchyma cells adjacent to veins. In some veins, CC were stained weakly with anti-VPg antibodies, but in no veins were CC stained with anti-CP antibodies.

${ }^{c}$ Total number of veins in which virus-specific signals were observed among the several thousand veins that were analyzed.
} 


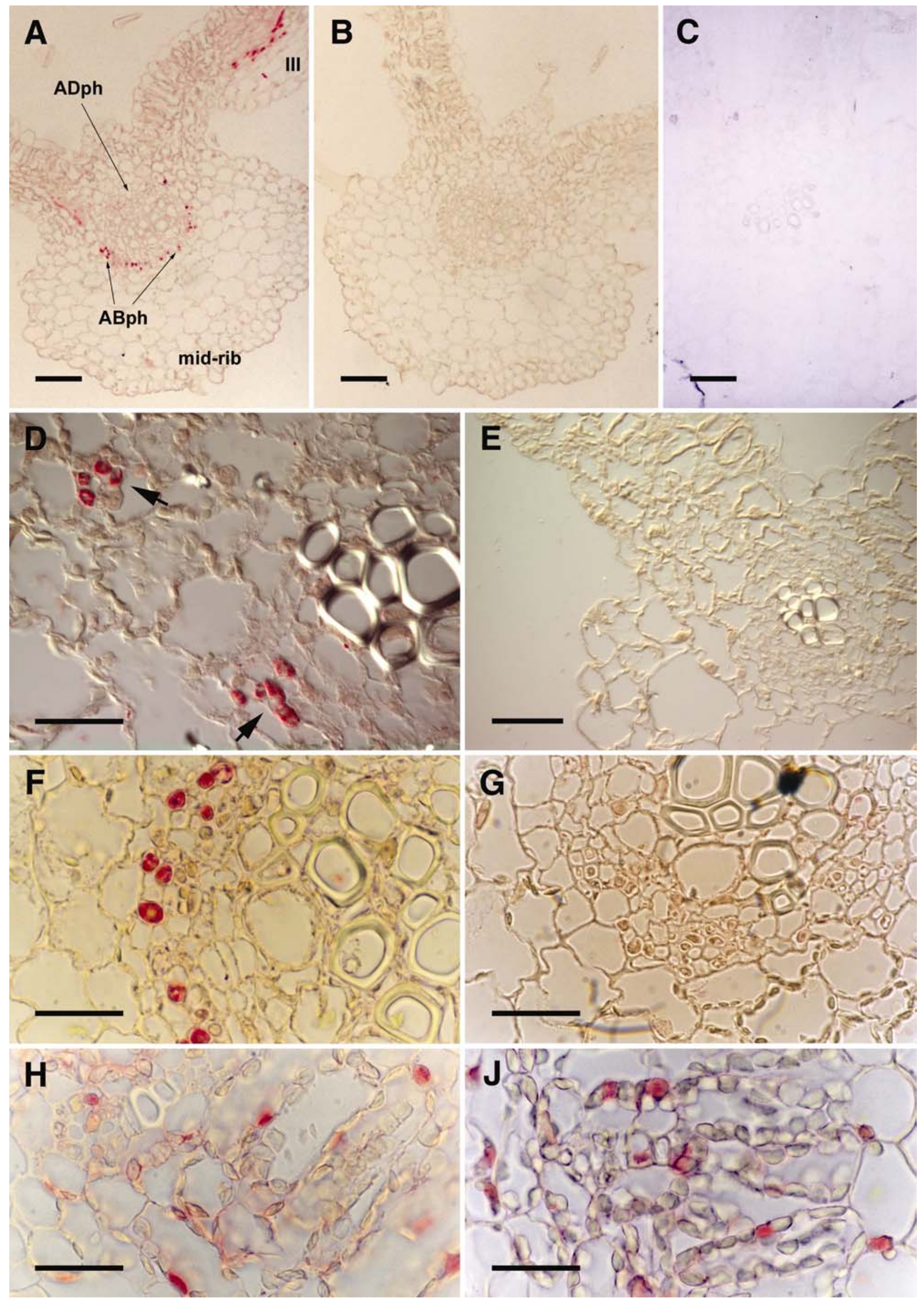


One aspect that requires further study is the role of the two types of phloem, $\mathrm{ADph}$ and $\mathrm{ABph}$, in virus unloading in the sink leaves in different virus-host combinations. In some cases, resistance to vascular movement of viruses includes a mechanism inhibiting virus entry to a specific phloem that is used for virus transport in susceptible host genotypes (Derrick and Barker 1997; Dufour et al. 1989; Murphy and Kyle 1995). This suggests that viruses are transported via a specific phloem route. In our study on $S$. commersonii, the initial systemic infection foci localized to the vicinity of $\mathrm{ABph}$ in the minor veins, as did the signals for VPg in all vein classes. Potato and $N$. bethamiana are related species of Solanaceae in which all vein classes contain $\mathrm{ABph}$ but the smallest veins lack $\mathrm{ADph}$ (Hayward 1938; McCauley and Evert 1988a, 1988b, 1989). In $N$. benthamiana, only the major veins can import and unload PVX-GFP and TMV (Roberts et al. 1997; Cheng et al. 2000). Therefore, while our data suggest that ABph may transport VPg and PVA into sink leaves in S. commersonii, the studies on PVX-GFP and TMV (Roberts et al. 1997; Cheng et al. 2000) suggest that both types of phloem are important for virus transport in $N$. benthamiana.

The signals for the VPg (N-proximal part of the NIa protein) in the sink leaves were observed in $\mathrm{CC}$ in an apparent absence of NIapro (C-proximal part of NIa), CP, other PVA proteins, and viral RNA. It is conceivable that not all VPg is linked to viral RNA during the infection cycle, and as such, the name of the protein may not fully describe its forms of existence in infected plants. The potyvirus proteins are produced in equimolar amounts in infected cells (Riechmann et al. 1992; Shukla et al. 1994). In the virions of PVA, one molecule of VPg is linked to the 5' end of viral RNA in the processed form, i.e., without the NIapro domain (Oruetxebarria et al. 2001). However, formation of virions requires approximately 2,000 units of $\mathrm{CP}$ per viral genomic strand (Shukla et al. 1994), making almost all VPg redundant at the encapsidation stage. Thus, the existence of VPg free from other viral components in $\mathrm{CC}$ of sink leaves may be explained with transport of VPg to sink leaves from the cells of the lower, PVAinfected source leaves in which infection of cells has advanced to the encapsidation stage. The 3a MP of Cucumber mosaic virus (CMV, genus Cucumovirus) can enter SE of minor veins in the inoculated leaves of $N$. clevelandii, in which it associates with the parietal layer of mature SE and is localized extensively in PD connecting SE and CC (Blackman et al. 1998). The upper noninoculated leaves were not tested for the $3 \mathrm{a} \mathrm{MP}$, but it was proposed that the 3a MP may be translocated via SE (Blackman et al. 1998). Also, the 17-kDa movement protein of PLRV is localized to PD and proposed to aid virus movement between the SE and CC (Schmitz et al. 1997; Tacke et al. 1993). The 17-kDa protein of PLRV has some similarities with the PVA VPg; both form homodimers and are phosphorylated (Guo et al. 2001; Ivanov et al. 2001; Oruetxebarria et al. 2001; Sokolova et al. 1997; Tacke et al. 1993). Taken together, our data and the similarities between PVA VPg and the other viral MPs suggest that accumulation of VPg in CC of the sink leaves may have functional significance for systemic infection with potyviruses.
Recent studies indicate that the potyviral VPg is an important virulence determinant since mutations in VPg can inhibit virus replication (Borgstrom and Johansen 2001; Keller et al. 1998), cell-to-cell movement (Nicolas et al. 1997), or vascular movement (Rajamäki and Valkonen 1999, 2002; Schaad et al. 1997). In the leaves of $S$. commersonii inoculated with PVA, VPg is responsible for two independent functions. It is needed for virus loading into SE, and it regulates the level of virus accumulation in phloem cells (Rajamäki and Valkonen 2002). Consequently, the early accumulation of the 'free' VPg in CC in the sink leaves may also have functional significance. For example, VPg may be needed for suppression of putative host defense mechanisms that could otherwise inhibit virus unloading and replication. One of such antiviral mechanisms could be RNA silencing, which may be hyperactivate in the cells controlling phloem-loading and unloading (Marathe et al. 2000). In agreement with this hypothesis, VPg was observed in the $\mathrm{CC}$ of infection foci only at an early phase of systemic infection (Fig. 1G). Other viral proteins were not observed in $\mathrm{CC}$, consistent with their possible quick turnover or fast exit from CC. Consistent with these results, no detectable amounts of viral proteins are observed in CC of the PVA-infected source leaves in S. commersonii (Rajamäki and Valkonen 2002).

It is hypothesized that the VPg that becomes linked to viral RNA may be used as a targeting signal for viral RNA for, e.g., virus cell to cell movement or unloading from SE (Carrington et al. 1996). This hypothesis sounds conceivable, albeit in our study VPg and viral RNA were not colocalized in CC in the sink leaves. Apparently, selective mechanisms operate at the CC-SE complex level to control unloading of macromolecules in the sink leaves (Ruiz-Medrano et al. 2001). Consequently, phosphorylation and dephosphorylation of PVA VPg (Ivanov et al. 2001) might control translation of the viral genome during passage through the PD between vascular cells, analogous to the functions of the TMV 30K MP during viral movement between mesophyll cells (Karpova et al. 1997, 1999; Waigmann et al. 2000).

The reasons why PVA CP, CI, HCpro, and NIapro were not detected in $\mathrm{CC}$ of the sink leaves may be because these proteins are not transported over long distances in SE, they may not be unloaded from SE to CC, they may be quickly degraded in $\mathrm{CC}$, or a combination of some or all of these factors. In this respect, accumulation of $\mathrm{VPg}$ specifically in $\mathrm{CC}$ of the sink leaves was striking and suggested that the 'RNA-free VPg' may be a 'phloem protein'. Phloem proteins do not escape the SE-CC complex (Ruiz-Medrano et al. 2001). For example, the phloem-specific protein PP2 accumulates in CC and SE, whereas the protein PP1 is predominantly found in SE in the species of Cucurbitaceae. Neither protein exits the CC-SE complex in sink tissues (Golecki et al. 1999). The phloem protein CmPP16 of Cucurbita maxima structurally resembles some plant virus MPs, mediates its own cell-to-cell movement through the PD between SE and CC, and facilitates trafficking of a ribonucleoprotein complex through the PD (XoconostleCázeras et al. 1999). However, it is noteworthy that PD be-

Fig. 3. Conspicuous staining of companion cells (CC) exclusively with anti-genome-linked protein (VPg) antibodies in the major veins of upper noninoculated leaves. A, In the mid-rib (vein class I), VPg is detected in abaxial phloem (ABph), whereas no signals are observed in the adaxial phloem (ADph). Note that the signals for VPg are also observed in a major vein (class III) that was cut longitudinally (to the right). However, no signals are observed in the consecutive sections stained with antibodies to $\mathbf{B}$, coat protein (CP), or $\mathbf{C}$, following in situ hybridization for viral RNA. F, A close-up of A, better illustrates the strong staining of cells of ABph with antibodies to VPg. The absence of staining with antibodies to the C-terminal proteinase domain (NIapro) in G, a consecutive section shows that the cells stained in A, and F, contain exclusively VPg and not the unprocessed NIa. Similar results were obtained in major veins of class II. Conspicuous staining for $\mathbf{D}$, VPg is observed in vascular cells of ABph (arrowheads), but E, no staining is observed with antibodies to NIapro. In contrast, signals for $\mathbf{H}, \mathrm{VPg}$ and $\mathbf{J}$, NIapro are quite similarly distributed in mesophyll cells of the systemically infected leaf tissues, the strongly stained cell compartments probably representing nuclei. Scale bars $=100 \mu \mathrm{m}$ in A to C, $25 \mu \mathrm{m}$ in $\mathrm{D}, \mathrm{F}$ to $\mathrm{J}$, and $50 \mu \mathrm{m}$ in $\mathrm{E}$. 
tween SE and CC have a SEL of approximately $25 \mathrm{kDa}$ (Kempers and van Bel 1997) corresponding to the molecular mass of PVA VPg (Oruetxebarria et al. 2001). Thus, unloading of RNA-free VPg from SE to CC might not require an active process but could occur by diffusion, similarly to GFP (27 $\mathrm{kDa}$ ), known to passively diffuse from SE to CC (Imlau et al. 1999). On the other hand, PD connecting CC to other vascular cells and forming the symplastic transport pathway needed for virus loading and unloading during vascular transport are much more restrictive to diffusion of macromolecules. Diffusion of proteins larger than approximately $1 \mathrm{kDa}$ is not possible between most cells (Ruiz-Merano et al. 2001). VPg contains no predictable domains involved in membrane-targeting that could interfere with protein translocation, and the nuclear localization signals do not interfere with intercellular trafficking of proteins (Crawford and Zambryski 2001). Therefore, our data indicate that VPg remains restricted to the SE-CC complex in sink leaves by a mechanism that might be similar to the mechanism restricting other phloem proteins to the CC-SE complex.

Taken together, our previous study has shown that the VPg of PVA influences phloem-loading of PVA in the inoculated leaves of $S$. commersonii and regulates the level of virus accumulation in phloem cells. Data in this study show that VPg accumulates specifically in CC in veins of the sink leaves in $S$. commersonii, probably by vascular transport from the PVA-infected source leaves, and that its accumulation in $\mathrm{CC}$ at the systemic infection foci occurs only at an early phase of systemic infection. These findings emphasize the specific role of VPg as vascular movement protein of potyviruses.

\section{MATERIALS AND METHODS}

\section{Virus constructs, plants, and growth conditions.}

Two recombinant PVA strains (B11-v4 and B11-M2) accumulating to high titers and capable of efficient systemic movement in S. commersonii were used (Rajamäki and Valkonen 2002). Since no differences were observed in the results obtained with the two PVA mutants, the results were combined. The clone C1 of S. commersonii (PI 458319) was used. Plants were multiplied, inoculated with viruses, and grown in a growth chamber under highly controlled conditions. All materials and experimental procedures and conditions have been described in our previous report (Rajamäki and Valkonen 2002).

\section{Titration of antisera.}

Titration of the anti-CP and anti-VPg rabbit antisera was carried out using microtiter plates (Greiner Labortechnik, Frickenhausen, Germany) and purified recombinant $\mathrm{CP}$ and VPg proteins $(6 \times \mathrm{His}-\mathrm{CP}$ and MBP-VPg) expressed in $E$. coli (Merits et al. 1998, 1999). Concentrations of the recombinant proteins were determined by sodium dodecyl sulfate-polyacrylamide gel electrophoresis using known amounts of bovine serum albumin (BSA) for comparison. The recombinant proteins were diluted to similar concentrations with ELISA coating buffer (0.05 M sodium carbonate, $\mathrm{pH}$ 9.6), and similar amounts (50 ng) were transferred in aliquots of $100 \mu \mathrm{l}$ to the wells of an ELISA plate followed by incubation at $+37^{\circ} \mathrm{C}$ for $3 \mathrm{~h}$. The plate was emptied and blocked with $2 \%$ nonfat milk (in ELISA sample buffer: $0.02 \mathrm{M}$ phosphate buffer, $\mathrm{pH} 7.4,0.15 \mathrm{M} \mathrm{NaCl}$, $0.05 \%$ Tween-20, $2 \%$ polyvinylpyrrolidone, and $0.2 \%$ BSA) at room temperature for $45 \mathrm{~min}$. After removing the blocking solution, different dilutions of the anti-CP and anti-VPg antibodies $(1: 500,1: 2,500,1: 12,500,1: 25,000,1: 62,500$, $1: 125,000$, and 1:250,000) prepared in ELISA sample buffer were added to plates and were incubated at $+4^{\circ} \mathrm{C}$ overnight. The following day, detection was carried out with mouse anti- rabbit monoclonal antibodies conjugated with alkaline phosphatase (dilution 1:5,000) (Sigma, St. Louis). Color reactions were developed using $p$-nitrophenyl phosphate as a substrate, and absorbances were measured at $405 \mathrm{~nm}$ with a Benchmark microtiter plate reader (Bio-Rad Laboratories, Hercules, CA, U.S.A.).

\section{Localization of viral proteins and RNA using leaf sections.}

Sampling of the systemically infected leaves has been described above and was illustrated in our previous report (Rajamäki and Valkonen 2002). Similarly, the procedures for fixation, embedding and cutting the leaf samples, staining of sections with antibodies (using fuchsin), and probing the sections with an RNA probe for detection of viral RNA have been described (Rajamäki and Valkonen 2002). Polyclonal antibodies raised in rabbits to the PVA proteins CI, VPg, and NIapro were provided by A. Merits, University of Helsinki, Finland. The rabbit polyclonal antibodies to the PVA HCpro and CP were a gift from F. Rabenstein, Institute for Resistance Breeding and Pathogen Diagnostics, Aschersleben, Germany. The antibodies specific to viral proteins were diluted 1:500 (CI, $\mathrm{VPg}$, and NIapro) or 1:100 (HCpro and CP) for immunostaining of sections. These dilutions were chosen for use based on preliminary experiments to maximize the specific signals and minimize the background signals. The digoxigenin-labeled RNA probe complementary to the $\mathrm{CP}$-encoding sequence of PVA has been described (Rajamäki and Valkonen 2002).

Sections were studied and photographed (Nikon FX-35WA, Nikon, Tokyo) under a light microscope (Nikon Optiphot) with objectives of $10 x / 0.25,20 x / 0.4,40 x / 0.85$ or $100 x / 1.25$ (Nikon). Alternatively, sections were analyzed and images digitized using an interference contrast microscope (objectives, 40x/0.7, 100x/1.39 Pl NeoFluar) (Leica DMRXE, Leica Gmbh, Wetzlar, Germany) equipped with a digital camera system (Hmamatzu Inc., Japan) at the Biological Microscopy and Imaging Unit, Department of Evolutionary Biology, Uppsala University.

\section{ACKNOWLEDGMENTS}

We thank S. Gunnarsson for guidance in the light microscopy techniques and help in preparation of figures, and F. Rabenstein and A. Merits for antisera. Financial support from SJFR/Formas (grant 301.0663/00) is gratefully acknowledged.

\section{LITERATURE CITED}

Andersen, K., and Johansen, I. E. 1998. A single conserved amino acid in the coat protein gene of pea seed-borne mosaic potyvirus modulates the ability of the virus to move systemically in Chenopodium quinoa. Virology 241:304-311.

Bartels, R. 1971. Potato virus A. C.M.I./A.A.B. Descriptions of Plant Viruses No. 54. Commonwealth Mycological Institute and Association of Applied Biologists, Kew, Surrey, U.K.

Blackman, L. M., Boevink, P., Santa Cruz, S., Palukaitis, P., and Oparka, K. J. 1998. The movement protein of cucumber mosaic virus traffics into sieve elements in minor veins of Nicotiana clevelandii. Plant Cell 10:525-537.

Borgstrom, B., and Johansen, I. E. 2001. Mutations in Pea seedborne mosaic virus genome-linked protein VPg alter pathotype-specific virulence in Pisum sativum. Mol. Plant-Microbe Interact. 14:707-714.

Carrington, J. C., Haldeman, R., Dolja, V. V., and Restrepo-Hartwig, M. A. 1993. Internal cleavage and trans-proteolytic activities of the VPgproteinase (NIa) of tobacco etc potyvirus in vivo. J. Virol. 67:69957000.

Carrington, J. C., Kasschau, K. D., Mahajan, S. K., and Schaad, M. C. 1996. Cell-to-cell and long-distance transport of viruses in plants. Plant Cell 8:1669-1681.

Carrington, J. C., Jensen, P. E., and Schaad, M. C. 1998. Genetic evidence for an essential role for potyvirus CI protein in cell-to-cell movement. Plant J. 14:393-400. 
Cheng, N.-H., Su, C.-L., Carter, S. A., and Nelson, R. S. 2000. Vascular invasion routes and systemic accumulation patterns of tobacco mosaic virus in Nicotiana benthamiana. Plant J. 23:349-362.

Crawford, K. M., and Zambryski, P. C. 2000. Subcellular localization determines the availability of non-targeted proteins to plasmodesmatal transport. Curr. Biol. 10:1032-1040.

Crawford, K. M., and Zambryski, P. C. 2001. Non-targeted and targeted protein movement through plasmodesmata in leaves in different developmental and physiological states. Plant Physiol. 125:1802-1812.

Cronin, S., Verchot, J., Haldeman-Cahill, R., Schaad, M. C., and Carrington, J. C. 1995. Long-distance movement factor: A transport function of the potyvirus helper component proteinase. Plant Cell 7:549-559.

Derrick, P. M., and Barker, H. 1997. Short and long distance spread of potato leafroll luteovirus: Effects of host genes and transgenes conferring resistance to virus accumulation in potato. J. Gen. Virol. 78:243 251

Ding, X. S., Carter, S. A., Deom, C. M., and Nelson, R. S. 1998. Tobamovirus and potyvirus accumulation in minor veins of inoculated leaves from representatives of the Solanaceae and Fabaceae. Plant Physiol. 116:125-136.

Dolja, V. V., Haldeman-Cahill, R., Montgomery, A. E., Vandenbosch, K A., and Carrington, J. C. 1995. Capsid protein determinants involved in cell-to-cell and long-distance movement of tobacco etch potyvirus. Virology 206:1007-1016.

Dufour, O., Palloix, A., Selassie, K. G., Pochard, E., and Marchoux, G. 1989. The distribution of cucumber mosaic virus in resistant and susceptible plants of pepper. Can. J. Bot. 67:655-660.

Fellers, J., Wan, J., Hong, Y., Collins G. B., and Hunt, A. G. 1998. In vitro interactions between a potyvirus-encoded, genome-linked protein and RNA-dependent RNA polymerase. J. Gen. Virol. 79:2043-2049.

Golecki, B., Schulz, A., and Thompson, G. A. 1999. Translocation of structural P proteins in the phloem. Plant Cell 11:127-140.

Guo, D., Rajamäki, M.-L., Saarma, M., and Valkonen, J. P. T. 2001. Towards a protein interaction map of potyviruses: Protein interaction matrixes of two potyviruses based on the yeast two-hybrid system. J. Gen. Virol. 82:935-939.

Hayward, H. E. 1938. Solanaceae. Pages 514-549 in: Structure of Economic Plants. Macmillan, New York.

Imlau, A., Truernit, E., and Sauer, N. 1999. Cell-to-cell and long-distance trafficking of the green fluorescent protein in the phloem and symplastic unloading of the protein into sink tissues. Plant Cell 11:309-322.

Ivanov, K. I., Puustinen, P., Merits, A., Saarma, M., and Mäkinen, K 2001. Phosphorylation down-regulates the RNA binding function of the coat protein of Potato virus A. J. Biol. Chem. 276:13530-13540.

Karpova, O. V., Ivanov, K. I., Rodionova, N. P., Dorokhov, Yu, L., and Atabekov, J. G. 1997. Nontranslatability and dissimilar behavior in plants and protoplasts of viral RNA and movement protein complexes formed in vitro. Virology 230:11-21.

Karpova, O. V., Rodionova, N. P., Ivanov, K. I., Kozlovsky, S. V., Dorokhov, Y. L., and Atabekov, J. G. 1999. Phosphorylation of tobacco mosaic virus movement protein abolishes its translation repressing ability. Virology 261:20-24.

Kasschau, K. D., and Carrington, J. C. 2001. Long-distance movement and replication maintenance functions correlate with silencing suppression activity of potyviral HC-Pro. Virology 285:71-81.

Kasschau, K. D., Cronin, S., and Carrington, J. C. 1997. Genome amplification and long-distance movement functions associated with the central domain of tobacco etch potyvirus helper component-proteinase. Virology 228:251-262.

Keller, K. E., Johansen, I. E., Martin, R. R., and Hampton, R. O. 1998 Potyvirus genome-linked protein (VPg) determines pea seed-borne mosaic virus pathotype-specific virulence in Pisum sativum. Mol. Plant-Microbe Interact. 11:124-130.

Kempers, R., and van Bel, A. J. E. 1997. Symplasmic connections between sieve element and companion cell in the stem phloem of Vicia faba L. have a molecular exclusion limit of at least $10 \mathrm{kD}$. Planta 201:195-201.

Lazarowitz, S. G., and Beachy, R. N. 1999. Viral movement proteins as probes for intracellular and intercellular trafficking in plants. Plant Cell 11:535-548

Li, X. H., Valdez, P., Olvera, R. E., and Carrington, J. C. 1997. Functions of the tobacco etch virus RNA polymerase (NIb): Subcellular transport and protein-protein interactions with $\mathrm{VPg} /$ proteinase (NIa). J. Virol. 71:1598-1607.

Marathe, R., Anandalakshmi, R., Smith, T. H., Pruss, G. J., and Vance, V. B. 2000. RNA viruses as inducers, suppressors and targets of post-transcriptional gene silencing. Plant Mol. Biol. 43:295-306.

Masuta, C., Nishimura, M., Morishita, H., and Hataya, T. 1999. A single amino acid change in viral genome-associated protein of potato virus Y correlates with resistance breaking in 'Virgin A Mutant' tobacco.
Phytopathology 89:118-123.

McCauley, M. M., and Evert, R. F. 1988a. Morphology and vasculature of the leaf of potato (Solanum tuberosum). Amer. J. Bot. 75:377-390.

McCauley, M. M., and Evert, R. F. 1988b. The anatomy of the leaf of potato, Solanum tuberosum L. 'Russet Burbank'. Bot. Gaz. 149:179-195.

McCauley, M. M., and Evert, R. F. 1989. Minor veins of the potato (Solanum tuberosum L.) leaf: Ultrastructure and plasmodesmatal frequency. Bot. Gaz. 150:351-368.

Merits, A., Guo, D., and Saarma M. 1998. VPg, coat protein and five non-structural proteins of potato A potyvirus bind RNA in a sequenceunspecific manner. J. Gen. Virol. 79:3123-3127.

Merits, A., Guo, D., Järvekülg, L., and Saarma, M. 1999. Biochemical and genetic evidence for interactions between potato A potyvirus-encoded proteins $\mathrm{P} 1$ and $\mathrm{P} 3$ and proteins of the putative replication complex. Virology 263:15-22.

Murphy, J. F., and Kyle, M. M. 1995. Alleviation of restricted systemic spread of pepper mottle potyvirus in Capsicum annuum cv. Avelar by coinfection with a cucumovirus. Phytopathology 85:561-566.

Murphy, J. F., Rychlik, W., Rhoads, R. E., Hunt, A. G., and Shaw, J. G. 1991. A tyrosine residue in the small nuclear inclusion protein of tobacco vein mottling virus links the VPg to the viral RNA. J. Virol. 65:511-513.

Murphy, J. F., Klein, P. G., Hunt, A. G., and Shaw, J. G. 1996. Replacement of the tyrosine residue that links a potyviral VPg to the viral RNA is lethal. Virology 220:535-538.

Nelson, R. S., and van Bel, A. J. E. 1998. The mystery of virus trafficking into, through and out of vascular tissue. Prog. Bot. 59:476-533.

Nicolas, O., Dunnington, S. W., Gotow, L. F., Pirone, T. P., and Hellmann, G. M. 1997. Variations in the VPg protein allow a potyvirus to overcome va gene resistance in tobacco. Virology 237:452-459.

Oparka, K. J., Roberts, A. G., Boevink, P., Santa Cruz, S., Roberts, I., Pradel, K. S., Imlau, A., Kotlizky, G., Sauer, N., and Epel, B. 1999. Simple, but not branched, plasmodesmata allow the nonspecific trafficking of proteins in developing tobacco leaves. Cell 97:743-754.

Oparka, K. J., and Santa Cruz, S. 2000. The great escape: Phloem transport and unloading of macromolecules. Annu. Rev. Plant Physiol. Plant Mol. Biol. 51:323-347.

Oruetxebarria, I., Guo, D., Merits, A., Mäkinen, K., Saarma, M., and Valkonen, J. P. T. 2001. Identification of the genome-linked protein in virions of Potato virus A, with comparison to other members in the genus Potyvirus. Virus Res. 73:103-112.

Paul, A. V., van Boom, J. H., Filippov, D., and Wimmer, E. 1998. Proteinprimed RNA synthesis by purified poliovirus RNA polymerase. Nature 393:280-284

Rajamäki, M.-L., and Valkonen, J. P. T. 1999. The 6K2 protein and the VPg of potato virus A are determinants of systemic infection in Nicandra physaloides. Mol. Plant-Microbe Interact. 12:1074-1081.

Rajamäki, M.-L., and Valkonen, J. P. T. 2002. Viral genome-linked protein (VPg) controls accumulation and phloem-loading of a potyvirus in inoculated potato leaves. Mol. Plant-Microbe Interact. 15:138-149.

Rhee, Y., Tzfira, T., Chen, M.-H., Waigmann, E., and Citovsky, V. 2000. Cell-to-cell movement of tobacco mosaic virus: Enigmas and explanations. Mol. Plant Pathol. 1:33-39.

Riechmann, J. L., Lain, S., and Garcia, J. A. 1992. Highlights and prospects of potyvirus molecular biology. J. Gen. Virol. 73:1-16.

Roberts, A. G., Santa Cruz, S., Roberts, I. M., Prior, D. A. M., Turgeon, R., and Oparka, K. J. 1997. Phloem unloading in sink leaves of Nicotiana benthamiana: Comparison of a fluorescent solute with a fluorescent virus. Plant Cell 9:1381-1396.

Rojas, M. R., Zerbini, F. M., Allison, R. F., Gilbertson, R. L., and Lucas, W. J. 1997. Capsid protein and helper component-proteinase functions as potyvirus cell-to-cell movement proteins. Virology 237:283-295.

Ruiz-Medrano, R., Xoconostle-Cazares, B., and Lucas, W. J. 2001. The phloem as a conduit for inter-organ communication. Curr. Opin. Plant Biol. 4:202-209.

Santa Cruz, S. 1999. Perspective: Phloem transport of viruses and macromolecules—what goes in must come out. Trends Microbiol. 7:237-241.

Savenkov, E. I., and Valkonen, J. P. T. 2001. Potyviral helper-component proteinase expressed in transgenic plants enhances titers of Potato leaf roll virus but does not alleviate its phloem limitation. Virology 283:285-293

Schaad, M. C., and Carrington, J. C. 1996. Suppression of long-distance movement of tobacco etch virus in a nonsusceptible host. J. Virol 70:2556-2561.

Schaad, M. C., Haldeman-Cahill, R., Cronin, S., and Carrington J. C. 1996. Analysis of the VPg-proteinase (NIa) encoded by tobacco etch potyvirus: Effects of mutations on subcellular transport, proteolytic processing and genome amplification. J. Virol. 70:7039-7048.

Schaad, M. C., Lellis, A. D., and Carrington, J. C. 1997. VPg of tobacco etch potyvirus is a host genotype-specific determinant for long-dis- 
tance movement. J. Virol. 71:8624-8631.

Schmalstig, J. G., and Geiger, D. R. 1987. Phloem unloading in developing leaves of sugar beet. Plant Physiol. 83:49-52.

Schmitz, J., Stussi-Garaud, C., Tacke, E., Prüfer, D., Rohde, W., and Rohfritsch, O. 1997. In situ localization of the putative movement protein (pr17) from potato leafroll luteovirus (PLRV) in infected and transgenic potato plants. Virology 235:311-322.

Shukla, D. D., Ward, C. W., and Brunt, A. A. 1994. The Potyviridae. C.A.B. International, Littlehampton, U.K.

Sokolova, M., Prüfer, D., Tacke, E., and Rohde, W. 1997. The potato leafroll virus $17 \mathrm{~K}$ movement protein is phosphorylated by a membraneassociated protein kinase from potato with biochemical features of protein kinase C. FEBS (Fed. Eur. Biochem. Soc.) Letters 400:201-205.

Sudarshana, M. R., Wang, H. L., Lucas, W. J., and Gilbertson, R. L. 1998. Dynamics of bean dwarf mosaic geminivirus cell-to-cell and long-distance movement in Phaseolus vulgaris revealed, using the green fluorescent protein. Mol. Plant-Microbe Interact. 11:277-291.

Tacke, E., Schmitz, J., Prüfer, D., and Rohde, W. 1993. Mutational analysis of the nucleic acid-binding $17 \mathrm{kDa}$ phosphoprotein of Potato leafroll luteovirus identifies an amphipathic $\alpha$-helix as the domain for protein/protein interactions. Virology 197:274-282.

Turgeon, R. 1989. The sink-source transition in leaves. Annu. Rev. Plant Physiol. Plant Mol. Biol. 40:119-138.

Tzfira, T., Rhee, Y., Chen, M.-H., Kunik, T., and Citovsky, V. 2000. Nucleic acid transport in plant-microbe interactions: The molecules that walk through the walls. Annu. Rev. Microbiol. 54:187-219.

Van Bel, A. J. E., Ehlers, K., and Knoblauch, M. 2002. Sieve elements caught in the act. Trends Plant Sci. 7:126-132.

Varrelmann, M., and Maiss, E. 2000. Mutations in the coat protein gene of Plum pox virus suppress particle assembly, heterologous encapsidation and complementation in the transgenic plants of Nicotiana benthamiana. J. Gen. Virol. 81:567-576.

Waigmann, E., Chen, M. H., Bachmaier, R., Ghoshroy, S., and Citovsky V. 2000. Regulation of plasmodesmal transport by phosphorylation of tobacco mosaic virus cell-to-cell movement protein. EMBO (Eur. Mol Biol. Organ.) J. 19:4875-4884.

Xoconostle-Cazares, B., Yu, X., Ruiz-Medrano, R., Wang, H. L., Monzer, J., Yoo, B. C., McFarland, K. C., Franceschi, V. R., and Lucas, W. J. 1999. Plant paralog to viral movement protein that potentiates transport of mRNA into the phloem. Science 283:94-98. 